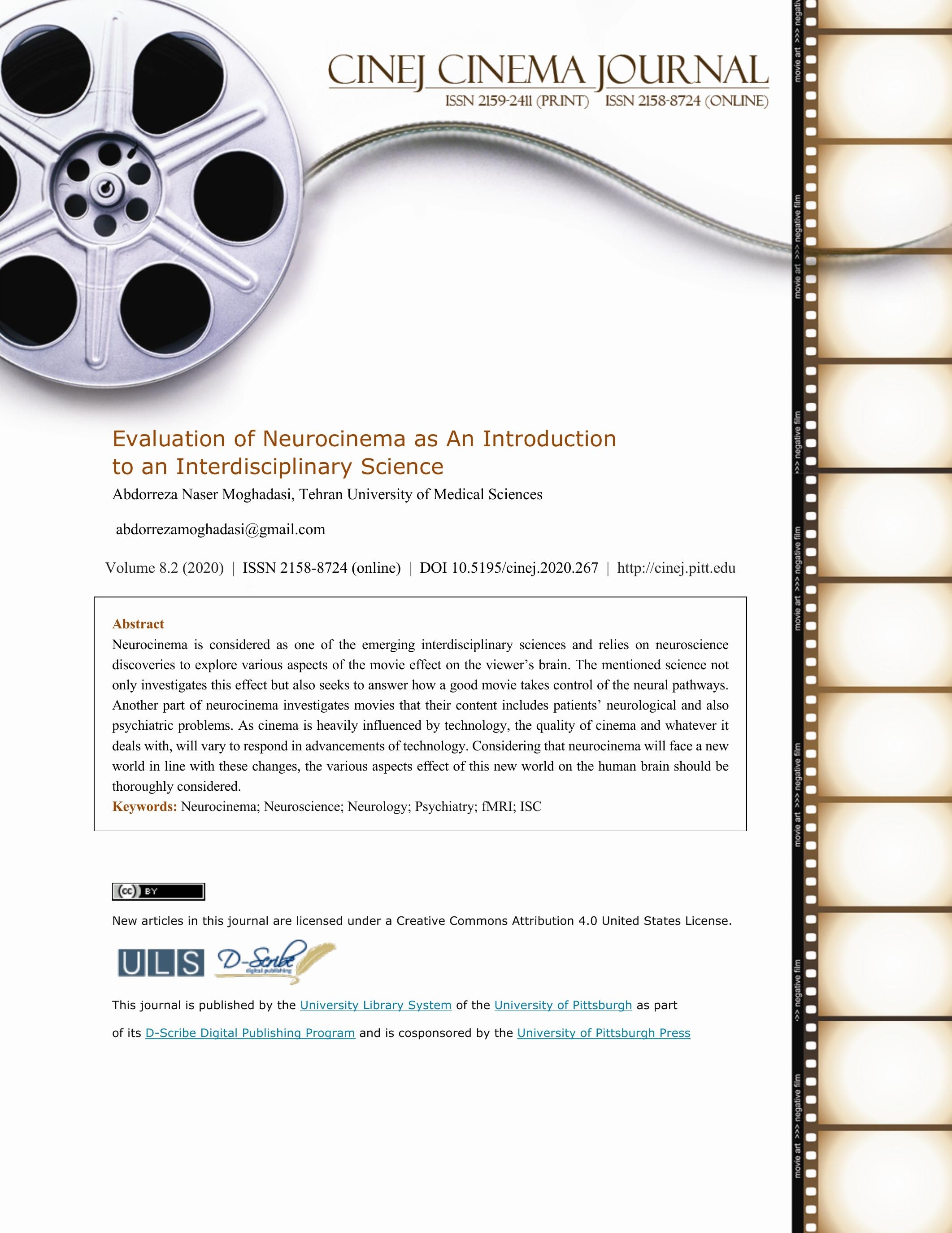




\section{Evaluation of Neurocinema as an Introduction to an Interdisciplinary Science ${ }^{1}$ Abdorreza Naser Moghadasi}

\section{Introduction}

In the last few years, the new field of neurocinema has more and more attracted the researchers' attention in the film studies. Neurocinema is simply evaluation of different properties of a movie by the neuroscience. This simple definition provides further studies in this case and leads to more productivity of this field of study ultimately. In fact, neurocinema can include any subjects which deal with the relationship between cinema and neuroscience. However, the mentioned diversity also causes some confusion because the capabilities of this field are vanished under a bunch of secondary information. As it will be indicated in the following parts, some parts of the neurocinema deal with a very high volume of movies, which address various neurological problems. These movies are sometimes very famous and valuable cinematically. Movies like Psycho (1960) by Hitchcock or One Flew over the Cuckoo's Nest (1975) by Milos Forman are examples of cinematic masterpieces which focus on mental disorders. Undoubtedly, although it is very significant to investigate how such movies approach the mental disorders, these issues are merely a by-product of neurocinema. Therefore, a categorization of what neurocinema has provided so far, should be presented before the various reviews which distract the researchers from reviewing and organizing this interdisciplinary science. This categorization can help the researchers in future studies. As the motion picture is the main issue in cinema, it is significant to investigate how the image and motion are processed in the brain. 


\section{Image and motion processing as well as selective attention in the brain}

Image processing first occurs in a region of brain called V1, which recognizes the basic properties of an image such as its horizontal or vertical position and also the contrast of the image with its surrounding area. Then, more specialized brain regions such as V2, V3, and V4 cooperate with each other to understand more complex issues such as the color and motion. However, no details of the image attract the viewer's attention equally. For example, it has been proven that the brain responds to brighter or vertical lines more. When the viewer looks at an image, only its small portion is considered by the brain, and the viewer cannot fully process a single image at a time (Tatler et al 2005). This processing and whatever the viewer notices, are the results of a complex process in the brain and are subject to various factors such as the location or properties of an object (Marinato \& Baldauf 2019). It should be considered that this selective attention shapes the realization and the consciousness content (Graziano 2019). To better understanding the issue, the following question should be answered: how does a viewer come to a mental experience of a subject? Graziano recommends a new approach to this issue. First, he deals with a selective signal enhancement. How is a signal taken into account and amplified by an organism at the same time? He considers the creation time of this mechanism, in creatures as the Cambrian period, is related to 550 million years ago. Selective attention has a profound effect on the behavior of any living creature. When an issue is highlighted and reinforced in the brain, it can impose a significant effect on the behavior of the creature in comparison with the effect of any other signals and stimuli. In the evolution, this amplified signal mechanism creates an internal model for attention. If the brain does a complex task, it must have an internal model to simulate that task dynamically, monitor its condition and environment during doing the task, and anticipate the next event. As neural processes become more complex in the course of evolution, these models become more complicated and perhaps extended. At first, this model was rudimentary but it has become more sophisticated and 
complex. Ultimately, this amplified signal mechanism creates a kind of attention schema, which plays a central role in the creation of consciousness (Graziano et al 2014).

This patterning or modeling of the brain plays an important role in our understanding of the surrounding world. According to this theory, the brain's attention to a phenomenon is facilitated when it has an internal pattern for considering the phenomenon. Such a model forms the foundations of consciousness (Graziano \& Webb 2015). Therefore, any selective attention reflects the content of our consciousness in some way. All senses are involved in the creation of this selective attention. However, there is an emphasizing on the visual system, considering the present subject.

This attention has quite different stages according to the visual perspective (Wen et al 2019); everything starts with the sensory organs, especially the eye, which is the brain's first way of visually communicating with the external world. If the eyes did not exist, we could not see the external world. The first stimuli, which enter the brain visually, pass through the eyes. The stimuli with special characteristics attract the attention of the human being. Likewise, the art offering more features of human interest can be more visually appealing for the brain. The presented concise introduction reveals that, two issues should be addressed with regard to neurocinema. First, why cinema can be successful as a visual stimulus? Secondly, when a movie attracts the attention of the audience, what are its peculiar features in terms of neurocinema?

\section{Cinema as a new stimulus for the brain}

Understanding various dimensions of cinema is very essential in this regard. In comparison with other forms of art, cinema is more dependent on technology. The presence of technology has provided various aspects to this new form of art, and this presence is increasingly taking on new 
dimensions. However, cinema is based on the most basic form of technology, i.e. the motion picture concept. The first images, which came out on the cinema, reflected the mentioned issue as they had neither sound nor color. They were only a motion picture on the screen, which influenced the audience strongly. Although the animation history started long before the development of cinema and its earliest evidence was related to the "Burnt City" belonging to 5000 years ago (Naser Moghadasi 2014), cinema with its profound effect on the audience was created with the invention of cinematography by Léon Bouly and then by The Lumière brothers. Previous motion pictures did not have such an effect on the audience. The invented device could not only record the video, but it could also act as a projector, which demonstrates the video on the screen (Abel 2004).

A neurocinematic perspective should be used to better understand the subject. As it has been mentioned, the world's first animation is the "Burnt City", which is depicted on a clay pot (Fig. 1) indicates this animation consists of five different sequences. The audience's view from the animation is what is important in the present discussion. The pot is in his hand and he looks at different sequences and eventually tells a story of these sequences. However, there is no direct emotional effect. Still, the motion does not have an external existence as we consider in the cinematography, and none of these attempts can represent the depth of the image (Wade 2016).

Indisputably, it is the photograph, which has transformed the motion picture. If we have a lot of cameras, each taking a sequence at a specific time interval, we can finally have a motion picture of the target subject. This is what Eadweard Muybridge did by photography of a horse called “Sallie Gardner" (Shimamura 2002).

Muybridge's work was a great transformation undeniably; however, its small size reduced its effectiveness. In the previous part, the importance of taking the control of the audience's eyes by the image was discussed. Practically, cinematography made it possible for cinema to take control of the audience's eyes. The cinematography encompasses three fundamental elements, 
such as camera, film, and light projection (Keating et al 2008). The cinematography makes the place and time come under the control of the film by helping the mentioned elements. The size of the movie screen covers virtually the audience's entire field of view. So regardless of the nature of the film, the movie screen itself plays the most important role to control the audience's eye movements. The movie screen in combination with the cinematography virtually covers the audience's entire field of view. As it has been mentioned, the first produced films were representing a simple event, for example trains running on rails. However, suppose the psychological and emotional burden of the audience sitting in front of the big screen and for the first time watching the train running toward him. This is the dominance of the cinema on audience's eye movements.

Dependence of cinema on the concept of motion is one its feature which is concealed in the aforementioned discussion. Cinema is distinguished from other forms of art by a concept which is called motion. Although it is true that cinema is fast going beyond the motion pictures, motion is the most important aspect of cinema as an art and distinguishes it from other forms of art. Neither two features of audio or color nor any other features can be regarded as the main feature of the cinema. Cinema is primarily a motion picture, which can have a profound effect on the mind and emotion of the audience.

In both theory and practice, cinema carries the concepts of time and place. Although time changes definitely, the location may be fixed and usually changes considering the narrative nature of the cinema. Therefore, cinema is very similar to real life but is not an imitation of it. Cinema, by its very nature, goes beyond photography, which is the record of events at a moment in time. Instead, cinema captures moments, deceives the brain by connecting them together, and delivers a 
sense of motion ultimately. The mentioned feature has accompanied cinema since the beginning of its history and may have been its fundamental element.

Interestingly, although the first cinematographic productions were made from a film of the usual scenes of life such as a train running on a rail; filming in its cinematic sense quickly took control over the great human invention and led to production of great masterpieces, which were still based on motion pictures and control of human eye movements. They focused on human visual sense more than anything else. Hence, the visual feature of cinema is the other important feature of it, which is still concealed in the previous definitions. Although the auditory dimension was subsequently added to the cinema, the visual feature differentiates cinema from the other forms of art. The point that: why black and white silent films are still popular, and why silent cinema still encompasses a significant part of the cinematic masterpieces can be dealt with from the perspective of neurocinema. The following part provides a brief overview of this feature.

We perceive a major proportion of stimuli from the external world through our visual sense. Thereafter, hearing, touch, and taste senses are slightly responsible in this regard. If the visual system is investigated in the brain, it will be observed that the vision pathways have virtually dominated the brain. The eyes and the two optic nerves are located in the anterior region of the brain, while the region, which is responsible for visual processing, is located in the posterior part of the brain and in the occipital lobe (Sung \& Chuang 2010). Therefore, this large gap between the regions that receive and process the stimuli within the brain must be due to the importance of vision for the brain and the possibility of connecting the visual sense to other parts of the brain. When the bulk of the brain processes is affected by the visual sense, it is no longer a surprise that white and black silent films can still grasp the attention of audience.

The purposefulness of the provided stimuli is the other feature of the cinema. The audience does not watch a number of haphazard pictures on the screen. As it was already mentioned, 
although cinema is very similar to real life, it is not an imitation of it. Purposefulness of cinema, which is obtained by elements such as camera, camera angle, zooming, and editing is what makes it different from life. All of the mentioned features make it possible for cinema to affect the eyes and the brain processing ultimately. Cinema itself selects the stimuli, and by doing so, presents the stimuli to the brain for giving its full attention.

Last but not least is the experience that cinema provides for the audience. The cinematic experience is the ultimate product of all the above-mentioned features and also other features which are added to the cinema by making a good movie. The cinematic experience is a unique subject, which elucidates the major difference between cinema and the real life. The cinematic experience is a kind of cognition and understanding, which is shaped in the mind of audience as a result of confronting a movie. This experience can be very far from the ordinary life: times and places change rapidly and magical and irrational relationships are formed between the elements of the movie. However, they all come together in a way that can be processed and recognized by the brain of audience. This is what ultimately leads to a cinematic experience and drives us to watch the movie.

The cinematic experience was shaped by the production of the first movie in the world of cinema and at present is rapidly expanding. Sound entered the cinema industry with the advancement of technology. The sound follows the same features of the image. Therefore, it can be declared that sound must be purposeful and controlled. Not every kind of sound is allowed to enter the cinema. The sound should affect the audience. So, sound is also a specific concept in the cinema. Later on, black and white movies were replaced by color movies by developing color technology. At present, 3D-cinema, animated cinema, and thousands of other options have greatly enriched this cinematic experience and made cinema a more and more all-encompassing peculiar 
stimulus for the human brain. Conceivably, no other stimulus, as much as cinema, contains a large volume of different sensory stimuli and does not invade the brain with a remarkable volume of data. Sometimes, the mentioned diversity makes it challenging to investigate how cinema affects the brain. As cinema progresses, we need more and more new features to recognize it. Neurocinema is considered as one of the most important apparatuses to understand cinema and how it relates to the audience.

\section{Neurocinema and evaluation of various aspects of relationship between cinema and neuroscience}

Neurocinema is the study of various aspects of a movie from a neuroscience perspective. Neurocinema aims include answering how a movie can affect the audience's mind. How it is possible that the viewer is engrossed watching a movie and identifies with its characters? The evaluation of these issues will no longer be demanding by introducing the neuroscience in various fields of study, because one aspect of the neurocinema deals with a viewer sitting on a cinema chair and staring at the big screen. Human processing of what he sees including the movie projected on the screen is done by the brain, and the end product is obtained as a result of the reaction between the brain and the stimulus which enters the brain from the external world. Therefore, the abilities and characteristics of the brain should be investigated in order to realize the end product of watching a movie in addition to the capabilities of cinema

The most serious studies of neurocinema have been devoted to investigate the changes in the brain processing during watching a movie. From this point of view, neurocinema is not a very complex subject. Just watch one of the movie masterpieces by directors such as Hitchcock, Tarkovsky, or Bergman and see how the movie captivates you and captures your cognitive, emotional, and even physical aspects. This comprehensive response of the human body to a movie 
forms the basis of neuroscience. Evaluating manner of the mentioned response occurrence involves the laboratory aspect of neurocinema. Furthermore, the evaluation of the brain regions, which are activated during watching a movie helps us to understand how the brain and cinema interact. Various methods can be employed to meet the mentioned objective. The application of new imaging techniques, especially functional magnetic resonance imaging (fMRI) is considered one of the prevalent methods. In this method, the target brain is imaged during watching a movie, and the region or regions of the brain, which are activated while watching a movie is determined (Hasson et al 2004).

One of the new methods to specify the brain regions which is activated during movie watching is called inter-subject correlation (ISC), during that response time course is measured in a small, specific region of the audience's brain during watching a movie. Then, the same item is measured in the other audiences who watching the same movie. This measurement is repeated by focusing on different regions of the brain. Then, various audiences' brain regions that have similar response time are identified during watching movie. It is stated that, these regions are activated and engaged during watching the movie (Hasson et al 2008).

The authors of the above-mentioned study attribute the findings with respect to the activation of similar brain regions in different audiences during watching the same movie to the control of a good movie over the nervous responses of the audiences. In fact, a movie activates similar neural pathways in different audiences.

Hasson et al., used fMRI and ISC to investigate the brain changes of the audiences during watching a movie and found that a wide range of brain regions such as the visual and auditory regions, linguistic region called Wernicke's area which is involved in speech comprehension, emotional processing regions, also multi-sensory regions located in the parietal and temporal lobes 
are involved during watching a movie. The activation of similar regions in different audiences confirms the authors' justification, which expresses that watching a movie activates similar neural pathways in different audiences. Moreover, the mentioned findings reveal that a movie engages a large region of the brain because of its complex stimulatory properties. The extent of the involved regions is really significant during watching a good movie. The authors of the mentioned study considered Hitchcock's movies as excellent cases in this respect.

Furthermore, the mentioned study investigated the role of editing in a movie and found that editing sequences can have a profound effect on the cognitive response of the brain to a movie (Hasson 2008). The studies of Hasson et al., are one of the most important studies in the field of neurocinema. However, it should be noted that a good movie has other features which should be considered in neurocinematic studies.

For example, the mentioned study merely analyzed the response of the brain to a small portion of a movie and did not provide any information about what would happen to the brain processes after watching a two-hour movie and what would be the features of the cognitive consequences from the perspective of neuroscience? How would the thematic unity be maintained in the audience's mind during a long movie despite the visual and auditory changes of the sequences? How does the human brain psychologically follow a narrative story on the cinema screen? (Cutting \& Armstrong 2019).

Many more questions will come up during the investigation. Such studies seem to be at their infancy, and there is still a long way to go to provide a complete analysis of a good movie. Particularly, cinema can be regarded as a very significant exception among all forms of art. Cinema and technology are intertwined, and cinema is created by developing technology. This development of technology will continue, so undoubtedly the shape and content of the cinema will change with the ever-increasing development of technology. Any change will generate a new 
stimulus for the human brain and will provide new research area, consequently new results and conclusions. Hence, the findings of neurocinema can be actively improved.

In addition, cinema is heavily dependent on the human brain structure. Some aspects of this dependency were investigated. Furthermore, it can be mentioned that cinema acts as a kind of conscious experience because it has some effects on the brain and controls the neural functions of the brain during watching the movie. In fact, a good movie narrates a conscious experience that deeply engages the audience. This engagement is due to the similarity of the structure of the movie to that of the human mind (Naser Moghadasi 2015). Why does the audience familiar with a character who has no external existence and sometimes his irrational actions are justified in the movie? Why are fictional characters like Superman and Batman so popular? Why do the fans of Star Wars make long queue outside the cinema to be the first viewers of the new episode? What is there in the movie that engages human consciousness to such an extent? All of the mentioned points are rooted in the resemblance of the structure of movie to that human consciousness. The mentioned resemblance makes a good movie capture the human consciousness through its effect on vast neural networks. Consideration of this resemblance and evaluation of a movie in consciousness studies can open a new chapter in the neurocinema research.

As it was mentioned, neurocinema has other aspects as well. Cinema has the capacity to involve all of these issues due to its nature. In general, as cinema is an art of vision and motion at its most basic form, it engages many scholars, anthropologists, and artists. This broad spectrum definitely includes the physicians, patients, and their relationships as well (Aubert 2015).

One of the aspects worth mentioning is the movies, which have used different findings of neuroscience and also the features of neurological and psychiatric diseases to organize their content, and sometimes their subject is a specific disease. The relationship between cinema and 
the neuroscience is very long and goes back to the pre-cinematography era. We have already talked about Muybridge's efforts to create a motion picture. Concurrently, a neurologist named Francis Dercum began to work with him. He used Muybridge's technique to prepare motion pictures of various neurological patients with movement disorders. By doing so, he could classify and identify various movement disorders (Lanska 2015). A microbiologist named Jean Comandon used the cinematography to diagnose neurological diseases from 1918 up to 1920 (Lorusso et al 2015).

Magnus and Rademaker also produced movies from medical experiments on animals from 1908 up to 1940 and brought the use of cinematography in medicine to a new phase ( Koehler \& Lameris 2015). Therefore, it is not too far-fetched that, along with these scientific endeavors at the time of the cinematography formation, neurological and psychiatric problems entered the narrative field of cinema and developed the story of a movie. In a great book, Wijdicks has explored an array of movies, which are related to neurological disorders directly or indirectly (Wijdicks 2014). In addition, he has also dealt with neuroscience-related ethical issues, which are presented, in the movies. Other chapters in this book have focused on the neurologists involved in the movie as well as the documentaries addressing various neurological diseases. In other words, this valuable book aims at indicating how different aspects of neurological diseases and their associated treatment are manifested in cinema (Heitmann 2016).

The consideration of movies such as those did not deal with by Wijdicks is another aspect of neurocinema, which has been largely ignored. The content of the mentioned array of movies is not directly related to neuroscience; however, the total structure of the movie simulates our mental and brain processing. The movies that intentionally or unintentionally use the shape and format of the human brain and its manner of processing and narrate the film story in this structure. "Being John Malkovich" is a good sample in this regard that was produced in 1999 by Spike Jonze. A puppeteer discovers a portal accidentally that leads literally to the mind of John Malkovich. 
Anyone who enters the mentioned portal can see the world through the eyes of John Malkovich. Then he starts to make money by doing so. The skilled puppeteer can control the mind of John Malkovich with his supremacy, and that is where his puppet show makes sense. In one of the fantastic scenes of the movie, John Malkovich himself enters his own mind through the portal. This portal reminds the viewer of the neural pathways of the brain. Mastering these portals can lead to the mastery over the person. Furthermore, if we look at the world through someone's eyes, it is like experiencing the awareness from his perspective. The mentioned movie, which neurocinema has a lot to say about it, makes a good use of the brain structure, processes to develop its structure, and can be a good subject for neurocinema analyses.

\section{Neurocinema and the future of man}

Neurocinema is considered as a novel science; however, it should be kept in mind that cinema is still an emerging art despite its rapid growth. Neurocinema will certainly add to its richness by exploring different aspects of cinema as well as analyzing various movies. But it should be considered that as cinema takes advantage of different aspects of technology, the content of neurocinema will change as well. Neurocinema is considered as a science that is deeply dependent on the growth of technology. Except the cinema that will change in the shadow of technology, its target audience, i.e. the human species, is also changing. The emergence of cyborgs, a combination of human and machine, is one of the most serious scientific, philosophical, and ethical debates of this era. Will this hybrid human also go to the cinema? Otherwise, will technology allow him to play a movie directly inside his mind? What will be the product of this internal play of the movie and its interaction with the brain systems that include prostheses thanks to new technology? It seems that neurocinema should be prepared to answer very significant questions. 


\section{Conclusion}

Neurocinema is considered as an interdisciplinary science, which investigates various aspects of cinema and movies by relying on findings and methods used in the neuroscience. These aspects include analyzing how the viewer relates to a good movie. Moreover, neurocinema deals with movies, which use neuroscience, neurological diseases, or related issues in their structure or content. In addition, new aspects of neurocinema are evolving that add to the richness of this emerging science by developing technology and its increasing use in the cinema.

\section{BIBLIOGRAPHY}

Abel, R. (2004). Encyclopedia of Early Cinema. London: Routledge.

Aubert G. (2015). Cinema and Neuroscience: Development and Application of Cinematography in the Field of the Neurosciences. Journal of the History of the Neurosciences, 25(1): 1-2.

Cutting, J.E., Armstrong, K.L. Large-scale narrative events in popular cinema. (2019). Cogitive Research, 4(34), 1-18.

Graziano, M. S., Guterstam, A., Bio, B. J., \& Wilterson, A. I. (2020). Toward a standard model of consciousness: Reconciling the attention schema, global workspace, higher-order thought, and illusionist theories. Cognitive Neuropsychology, 37(3-4), 155-172.

Graziano, M. S., \& Webb, T. W. (2015). The attention schema theory: a mechanistic account of subjective awareness. Frontiers in psychology, 6, 500.

Graziano, M. S. (2014). Speculations on the evolution of awareness. Journal of cognitive neuroscience, 26(6), 1300-1304.

Hasson, U., Nir, Y., Levy, I., Fuhrmann, G., \& Malach, R. (2004). Intersubject synchronization of cortical activity during natural vision. science, 303(5664), 1634-1640. 
Hasson, U., Landesman, O., Knappmeyer, B., Vallines, I., Rubin, N., \& Heeger, D. J. (2008). Neurocinematics: The neuroscience of film. Projections, 2(1), 1-26.

Heitmann, H. (2016). Review of Neurocinema: When Film Meets Neurology. JAMA neurology, 73(1), 129-129.

Keating, P. (2014). Cinematography (Behind the Silver Screen Series). Newark, NJ: Rutgers University Press.

Koehler, P. J., \& Lameris, B. (2016). The Magnus-Rademaker Scientific Film Collection: Ethical Issues on Animal Experimentation (1908-1940). Journal of the History of the Neurosciences, 25(1), 102-121.

Lanska, D. J. (2016). The Dercum-Muybridge collaboration and the study of pathologic gaits using sequential photography. Journal of the History of the Neurosciences, 25(1), 23-38.

Lorusso, L., Lefebvre, T., \& De Pastre, B. (2016). Jean Comandon Neuroscientist. Journal of the History of the Neurosciences, 25(1), 72-83.

Marinato, G., \& Baldauf, D. (2019). Object-based attention in complex, naturalistic auditory streams. Scientific reports, $9(1), 1-13$.

Naser, A. M. (2015). Neurocinema: A brief overview. Iranian journal of neurology, 14(3), 180184.

Moghadasi, A. N. (2014). Artificial eye in burnt city and theoretical understanding of how vision works. Iranian journal of public health, 43(11), 1595-1596.

Poulaki, M. (2014). Neurocinematics and the discourse of control: Towards a critical neurofilmology. Cinéma \& Cie: International film studies journal, 22-23.

Shimamura, A. P. (2002). Muybridge in motion: Travels in art, psychology and neurology. History of Photography, 26(4), 341-350. 
Sung, C. H., \& Chuang, J. Z. (2010). The cell biology of vision. Journal of Cell Biology, 190(6), 953-963.

Tatler, B. W., Baddeley, R. J., \& Gilchrist, I. D. (2005). Visual correlates of fixation selection: Effects of scale and time. Vision research, 45(5), 643-659.

Wade, N. J. (2016). Capturing motion and depth before cinematography. Journal of the History of the Neurosciences, 25(1), 3-22.

Wen, T., Duncan, J., \& Mitchell, D. J. (2019). The time-course of component processes of selective attention. NeuroImage, 199, 396-407.

Weibel, P. (2003). The intelligent image: Neurocinema or quantum cinema. Future Cinema, 594601.

Wijdicks, F.M. (2014). Neurocinema: When Film Meets Neurology. Boca Raton, FL: CRC Press.

\section{ENDNOTES}

${ }^{1}$ Other articles on the neurocinema with extensive references to the subject are Weibel (2003) and Poulaki (2015). 